DOI: http://doi.org/10.21698/simi.2018.ab01

\title{
ASSESSMENT OF OPERATIONAL PARAMETERS IN THE PROCESS OF RECOVERY AND SEPARATION OF PHARMACEUTICAL PRODUCTS THROUGH THE TECHNIQUE OF BULK LIQUID MEMBRANES
}

Ecaterina Anca Serban ${ }^{1,2}$, Ioana Diaconu ${ }^{2}$, Elena Ruse ${ }^{2}$, Gheorghe Batrinescu ${ }^{1}$, Gheorghe Nechifor $^{2}$, Gabriela Geanina Vasile ${ }^{1}$

\footnotetext{
${ }^{1}$ National Research and Development Institute for Industrial Ecology ECOIND, 71-73 Drumul Podul Dambovitei, district 6, 060652, Bucharest, katyserban@yahoo.com, Romania

${ }^{2}$ University Politehnica of Bucharest, Faculty of Applied Chemistry and Materials Science, 1-7

Polizu Street, 011061, Bucharest, diaconuioana12@yahoo.com, Romania
}

Keywords: bulk liquid membrane transport, Nicotinic acid, p-aminobenzoic acid, separation of pharmaceutical products

\section{Introduction}

Bulk liquid membranes show an ample potential in the treatment and separation of pharmaceutical products from industrial effluents. In this present paper has been studied the behavior at the transport through a liquid membrane of chloroform containing Aliquat 336 of two pharmaceutical importance compounds, namely: nicotinic acid (vitamin $\mathrm{PP} / \mathrm{B}_{3}$ ) and $\mathrm{p}$-aminobenzoic acid (vitamin $\mathrm{B}_{10}$ ). The influence of operational parameters such as: the influence of the solute concentration in the feed phase, the influence of the stripping agent concentration in the stripping phase, transport time was monitored. The assessment of the obtained results allowed the identification of a kinetic transport model for nicotinic acid corresponding to consecutive irreversible 1 st order reactions. The results obtained led to important conclusions regarding the possibility of separating these two compounds. Analytical control of the process was performed spectrophotometrically. The maximum absorbance was obtained at their characteristic wavelengths, namely $262 \mathrm{~nm}$ for nicotinic acid and respectively $267 \mathrm{~nm}$ for p-aminobenzoic acid.

\section{Materials and methods}

All reagents used in the transport studies were of analytical grade and were used without further purification. Nicotinic acid, p-aminobenzoic acid and the carrier Aliquat 336 were purchased from Merck. The sodium hydroxide used as the stripping agent and the chloroform used as the membrane phase was obtained from Chimreactiv SRL. The transport experiments were carried out in a wall in wall transport cell. The membrane system consisted of: the feed phase - aqueous solution of nicotinic acid or p-aminobenzoic acid in the concentration range of $10^{-4}-10^{-3} \mathrm{~mol} / \mathrm{L}$, membrane Aliquat 336 solution, $10^{-2} \mathrm{~mol} / \mathrm{L}$ in chloroform, the stripping phase - solution of sodium hydroxide in the concentration range $10^{-2}-1 \mathrm{~mol} / \mathrm{L}$. For the preparation of the aqueous phases, distilled water saturated with chloroform was used and the preparation of the membrane phase used chloroform saturated with water. 


\section{INTERNATIONAL SYMPOSIUM "THE ENVIRONMENT AND THE INDUSTRY", SIMI 2018, BOOK OF ABSTRACTS}

\section{Results and conclusions}

The transport of organic compounds (mostly acids or organic bases) is based on a concentration gradient along the membrane sustained through irreversible chemical reactions of the solute with a strong base or a strong acid, dissolved in the acceptor phase. Thus in acceptor phase are obtained ion insoluble structures in the membrane phase are thus inactive for transport. The use of a carrier capable of complexing the solute increases its solubility in the membrane and thus leads to an increase in transport efficiency.

Aliquat 336 is a carrier is known as a good complexing agent of anionic species. Thus we have used of a membrane system formed by : the alkaline donor phase that provides a degree of anionic formation of more over $90 \%$ and an acid acceptor phase that predominantly transforms the organic substrate into an inactive cationic species. This system has not produced satisfactory results from the point of view of transport efficiency.

The best results are obtained from the transport of nicotinic acid from aqueous solutions without $\mathrm{pH}$ correction. Thus, using a feed phase by nicotinic acid at a concentration of $10^{-3} \mathrm{~mol} / \mathrm{L}$ and a acceptor phase of $\mathrm{NaOH}$ at a concentration of 1 $\mathrm{mol} / \mathrm{L}$, the transport efficiency are close to $90 \%$.

Following the variation of reduced concentrations in time for nicotinic acid transport under the above mentioned conditions, a kinetic model of order 1 with a degree of correlation greater than $99 \%$ was identified (Figure 1).

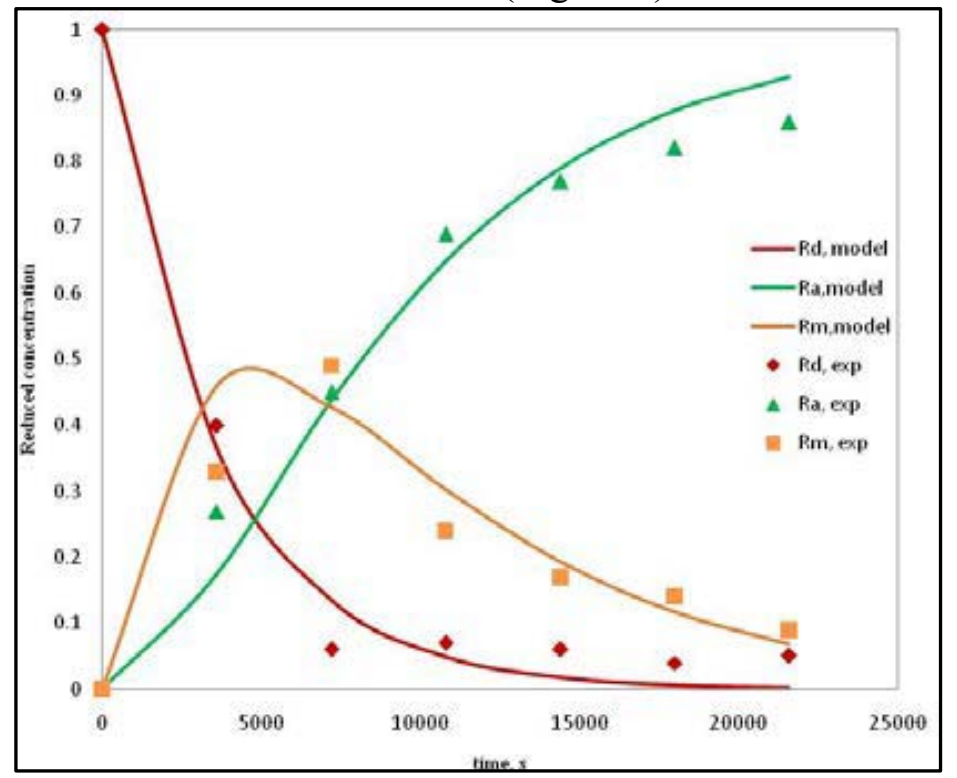

Figure 1. Transport of nicotinic acid; nicotinic acid donor phase $10^{-3} \mathrm{M}(\mathrm{d}), \mathrm{NaOH} 1 \mathrm{M}$ acceptor phase (a), membrane a solution Aliquat $33610^{-2} \mathrm{M}$ in chloroform (m). Rreduced concentration

Note that under the same transport conditions, p-aminobenzoic acid is transferred from the feed phase to the stripping phase in very small amounts which may be useful in separating these two compounds. 